\title{
Long-term trends in cardiovascular disease mortality and association with respiratory disease
}

\author{
A. J. MERCER* \\ Eynesbury, St Neots, Cambridgeshire, UK \\ Received 21 April 2015; Final revision 29 June 2015; Accepted 15 July 2015; \\ first published online 5 August 2015
}

\section{SUMMARY}

The recent decline in cardiovascular disease mortality in Western countries has been linked with changes in life style and treatment. This study considers periods of decline before effective medical interventions or knowledge about risk factors. Trends in annual age-standardized death rates from cerebrovascular disease, heart disease and circulatory disease, and all cardiovascular disease are reviewed for three phases, 1881-1916, 1920-1939, and 1940-2000. There was a consistent decline in the cerebrovascular disease death rate between 1891 and 2000, apart from brief increases after the two world wars. The heart disease and circulatory disease death rate was declining between 1891 and 1910 before cigarette smoking became prevalent. The early peak in cardiovascular mortality in 1891 coincided with an influenza pandemic and a peak in the death rate from bronchitis, pneumonia and influenza. There is also correspondence between short-term fluctuations in the death rates from these respiratory diseases and cardiovascular disease. This evidence of ecological association is consistent with the findings of many studies that seasonal influenza can trigger acute myocardial infarction and episodes of respiratory infection are followed by increased risk of cardiovascular events. Vaccination studies could provide more definitive evidence of the role in cardiovascular disease and mortality of influenza, other viruses, and common bacterial agents of respiratory infection.

Key words: Cardiovascular, cerebrovascular, heart disease, influenza, respiratory disease.

\section{INTRODUCTION}

Trends in cardiovascular disease (CVD) mortality varied considerably in industrialized countries in the second half of the 20th century. A consistent fall in male and female CVD death rates from the 1950s was reported for the UK, the United States, Canada, France, and Switzerland [1]. A decline was reported for most Western countries by the 1970s [2], and most had declining coronary heart disease (CHD) death rates by the 1980s or 1990s [3]. The

\footnotetext{
* Address for correspondence: Mr A. J. Mercer, 38 Wren Walk, Eynesbury, St Neots, Cambridgeshire PE19 2GE, UK. (Email: alecmercer@msn.com).
}

lack of decline in death rates in much of Eastern Europe and the Former Soviet Union was attributed to continuingly high prevalence of lifestyle-related risk factors $[4,5]$. Countries undergoing economic transition, and developing countries with more limited resources for prevention and treatment, were considered to be at an earlier stage of a 'heart disease epidemic' [6]. A vast body of research since the 1950s has identified major cardiovascular risk factors, including tobacco smoking, high blood pressure, high blood cholesterol, harmful diet, obesity, physical inactivity, low socioeconomic status, and low job control [7, 8]. International, geographical, and socioeconomic differences in the timing of heart disease 
mortality decline have suggested a process of diffusion of prevention and treatment measures [9, 10]. However, these do not explain some aspects of longterm trends in cardiovascular mortality, including considerable decline in cerebrovascular disease mortality in England and Wales and the United States long before effective medical interventions became available in the 1950s [11, 12].

There was a decline in cerebrovascular disease death rates for most Western countries in the second half of the 20th century. This was widely attributed to declining prevalence of the main risk factor, hypertension [12-14], although some studies suggest that anti-hypertension treatment explains a relatively small proportion of the decline [15]. The decline in cerebrovascular mortality in the United States contributed to a $60 \%$ reduction in the total CVD death rate between 1950 and 1996, which occurred despite an increase in the CHD death rate until 1963 [14]. Major risk factors for CHD, apart from hypertension, appear to be less significant for cerebrovascular disease [16], and the downturn in mortality in the United States coincided with public health warnings about risk factors [17]. Following prevention programmes focusing on cigarette smoking, diet, and physical exercise, there were beneficial changes in lifestyle, particularly in higher socioeconomic groups [18]. The decline in the CHD death rate between 1963 and 1982 coincided with a decline in prevalence of cigarette smoking, lower serum cholesterol levels, and beneficial changes in diet [19]. More than half the decline between 1968 and 1976 was associated with reductions in lifestyle-related risks, particularly reduced prevalence of cigarette smoking and lower serum cholesterol levels [20], while $40 \%$ was linked with medical interventions. About $70 \%$ of the decline in CHD mortality in the United States between 1980 and 1990 was in CHD patients [21]; $47 \%$ of the decline between 1980 and 2000 was attributed to treatment and $44 \%$ to changes in risk factors, particularly reductions in total cholesterol, systolic blood pressure, cigarette smoking, and physical inactivity [22]. A study of the decline in the ischaemic heart disease (IHD) death rate in England and Wales between 1981 and 2000 concluded that $42 \%$ was attributable to treatment for heart disease, and $58 \%$ to reductions in blood pressure, cholesterol levels, and cigarette smoking in particular [23]. Studies in several Western countries reported similar contributions to the decline associated with reductions in lifestyle-related risks $(40-60 \%)$ and treatment $(35-50 \%)$ [24-27].
Studies of trends in death rates from heart disease, stroke, or total CVD have generally not considered pathogenic mechanisms through which intermediate lifestyle-related risks contribute to cardiovascular disorders and fatal events. A growing body of evidence of association between CVD and infection suggests that certain common pathogens might be more proximate causes of the underlying disorders and potentially fatal cardiovascular events, within a multi-causal aetiology. In the early 20th century specific viruses were linked with different forms of heart disease, including endocarditis, pericarditis, and myocarditis [28]. Laboratory studies in the 1960s found that influenza and other viruses caused agglutination of blood platelets [29-31], which suggested a potential role in embolism and thrombosis, coronary artery disease, and cumulatively in atherosclerosis [32, 33]. Reviews of further studies up to the 1990s, found that the evidence generally indicated that infections may have a role in atherosclerosis [34, 35], and Chlamydia pneumoniae in particular is associated with both atherosclerosis and CHD [36-38]. Evidence from different types of study indicates that influenza is associated with CVD and may 'trigger' acute myocardial infarction [39-41], while Helicobacter pylori and bacterial respiratory infections are associated with stroke $[42,43]$.

Given the possible involvement of respiratory infections in different cardiovascular disorders, events, and mortality, insufficient attention has been given to changes in the 'infectious disease environment' as a possible influence on secular trends in mortality from heart disease and stroke, and the current predominance of chronic diseases may be better understood in the historical context of epidemiological transition [44]. Clearly, long-term trends in cardiovascular mortality need to be viewed with caution given the many changes in certification practice affecting sub-categories [16, 45]. Relatively few studies have focused on total CVD, or a combined group of heart and circulatory diseases (CD), which can overcome some of these problems [46]. In this paper we examine trends in death rates from cerebrovascular disease, heart disease and $\mathrm{CD}$, total $\mathrm{CVD}$, and respiratory diseases in England and Wales over the period $1881-2000$.

\section{METHODS}

The longest series of data on CVD deaths by age is that available from the Annual Reports of the 
Registrar General for England and Wales, and later government publications [47, 48]. Numbers of annual deaths in 5-year age groups were obtained from reports for 1881-1900 and a CD-ROM for 19002000 provided by the Office for National Statistics (ONS) [48]. Using population estimates based on census data, age-specific death rates were calculated for cerebrovascular disease, heart disease and $\mathrm{CD}$, and a group of respiratory diseases (bronchitis, pneumonia, and influenza). These rates were applied (direct method) to the European Standard Population (ESP) to produce annual age-standardized death rates [49]. For comparability over time, and consistency with trends reported for the 20th century in other studies, the 1976 ESP was used for the whole period 1881-2000. There were several changes in the International Classification of Diseases (ICD) between 1900 and 2000, some of which were quite disruptive of continuity, even in the later decades [50]. Comparability ratios to allow for the effect on CVD trends were generally not available for England and Wales. Estimates for the United States indicate little effect on trends in stroke mortality over the period 1940-2000, or on other CVD mortality apart from an increase when ICD-6 was introduced in 1949 (indicated by a gap in the trend in Fig. 3) [51]. Unadjusted trends are reviewed for three periods, 1881-1916, 1920-1939, and 1940-2000, within which the number of classification changes was limited and the proportion of deaths in the main categories was reasonably consistent. The categories included were consistent with those used by the ONS for examining national trends in mortality from stroke and diseases of the circulatory system in the 20th century [52]. For disease classification codes used see Table 1.

\section{RESULTS}

In the first phase of the historical trend in cardiovascular mortality shown in Figure 1 (1881-1916), the age-standardized death rate for all CVD increased up to 1891 and then declined until 1910. At this early peak, the cause of some cardiovascular deaths was specified: endocarditis $(11 \cdot 2 \%)$, syncope $(3 \cdot 2 \%)$, pericarditis $(0 \cdot 8 \%)$, aneurism $(0.9 \%)$, and 'angina pectoris' $(0 \cdot 9 \%)$. Most other deaths classified as diseases of the circulatory system were recorded as undefined heart disease and circulatory disorders $(47 \cdot 1 \%)$. The CVD deaths attributed to a group of cerebrovascular disorders $(35.9 \%)$ were mainly in adults, and most of those recorded as 'apoplexy' (21.6\%) were probably due to stroke. By the time of a peak in 1951, 24.7\% of CVD deaths were attributed to cerebrovascular diseases, $67 \cdot 7 \%$ to defined heart diseases, and $7 \cdot 6 \%$ to other circulatory disorders. CVD accounted for $48 \%$ of all deaths compared to only $13 \%$ in 1881 .

There was close similarity between the trend in death rates from heart disease/CD and the group of respiratory diseases, bronchitis, pneumonia and influenza over the period 1881-1916, in terms of short-term fluctuations and the major turning point in 1891 (Fig. 1). Both cerebrovascular disease and the larger group, heart disease/CD, contributed to the phase of declining cardiovascular mortality between 1891 and 1910. The cerebrovascular disease death rate declined by $30 \%$ in that period, a decline that continued in the inter-war years (Fig. 2) along with that for the respiratory diseases (not shown). By contrast, the death rates from heart disease/CD and all CVD increased between the wars, when shortterm fluctuations continued to correspond with those for influenza mortality (Fig. 2).

Following lower cardiovascular mortality in the 1940s, there was a peak in the death rate in 1951 (Fig. 3). More specific certification indicated that heart disease accounted for $90 \%$ of the heart disease/ CD category, which itself accounted for $74.3 \%$ of the total cardiovascular mortality decline between 1951 and 2000, while cerebrovascular disease accounted for $25 \cdot 7 \%$.

Cerebrovascular mortality declined fairly consistently from the 1890s, apart from a brief increase after each world war, and the overall trend was much the same for males and females. By contrast, there was a considerable increase in the death rate from heart disease/CD in the 1920s and 1930s, and a widening sex differential up to the 1970s (Figs 2 and 3). Even so, the long-term trend over the whole period 1881-2000 was much the same for males and females in terms of short-term fluctuations and major turning points in the death rates, which indicates exposure to a similar risk environment.

\section{DISCUSSION}

Interpretation of long-term trends in cardiovascular mortality requires considerable caution in view of limitations of the data. Quality and consistency have been affected by changes in diagnostic skills and practice, preference in assigning primary cause of death, and choice of ICD categories to include in major groups. Trends for relatively small disease categories are 
Table 1. Disease classification codes

\begin{tabular}{llll}
\hline \hline Classification & Cerebrovascular disease & Heart and circulatory disease & Respiratory disease \\
\hline 1881-1900 & $\begin{array}{c}\text { Apoplexy/hemiplegia, } \\
\text { softening of the brain }\end{array}$ & Circulatory diseases & $\begin{array}{c}\text { Bronchitis, pneumonia, } \\
\text { and influenza }\end{array}$ \\
1901-1910 (ICD-1) & $84,106,107$ & $63,64,99-105,108-113$ & $118,36-39,12$ \\
$1911-1920$ (ICD-2) & $64-66$ & $47,77-85,189 \mathrm{a}$ & $89-90,91-92,10$ \\
$1921-1930$ (ICD-3) & $74,75 \mathrm{a}, 83,91 \mathrm{~b}(1)$ & $51,81,87-96$ [not 91b(1)], 205(1) & $99,100-101,11$ \\
$1931-1939$ (ICD-4) & $82,97(1), 97(2)$ & $56,87 \mathrm{a}, 90-96,97(3), 99-103,200(1)$ & $106,107-109,11$ \\
$1940-1949$ (ICD-5) & 83 & $58,87 \mathrm{a}, 90-97,99-103,200 \mathrm{a}(1)$ & \\
$1950-1957$ (ICD-6) & $330-334$ & $400-454,456-468,782$ & \\
$1958-1967$ (ICD-7) & $330-334$ & $400-454,456-468,782$ & \\
$1968-1978$ (ICD-8) & $430-438$ & $390-429,440-444 \cdot 1,444 \cdot 4-458,782$ & \\
$1979-2000$ (ICD-9) & $430-438$ & $390-429,440-459$ & \\
\hline \hline
\end{tabular}

ICD, International Classification of Diseases.

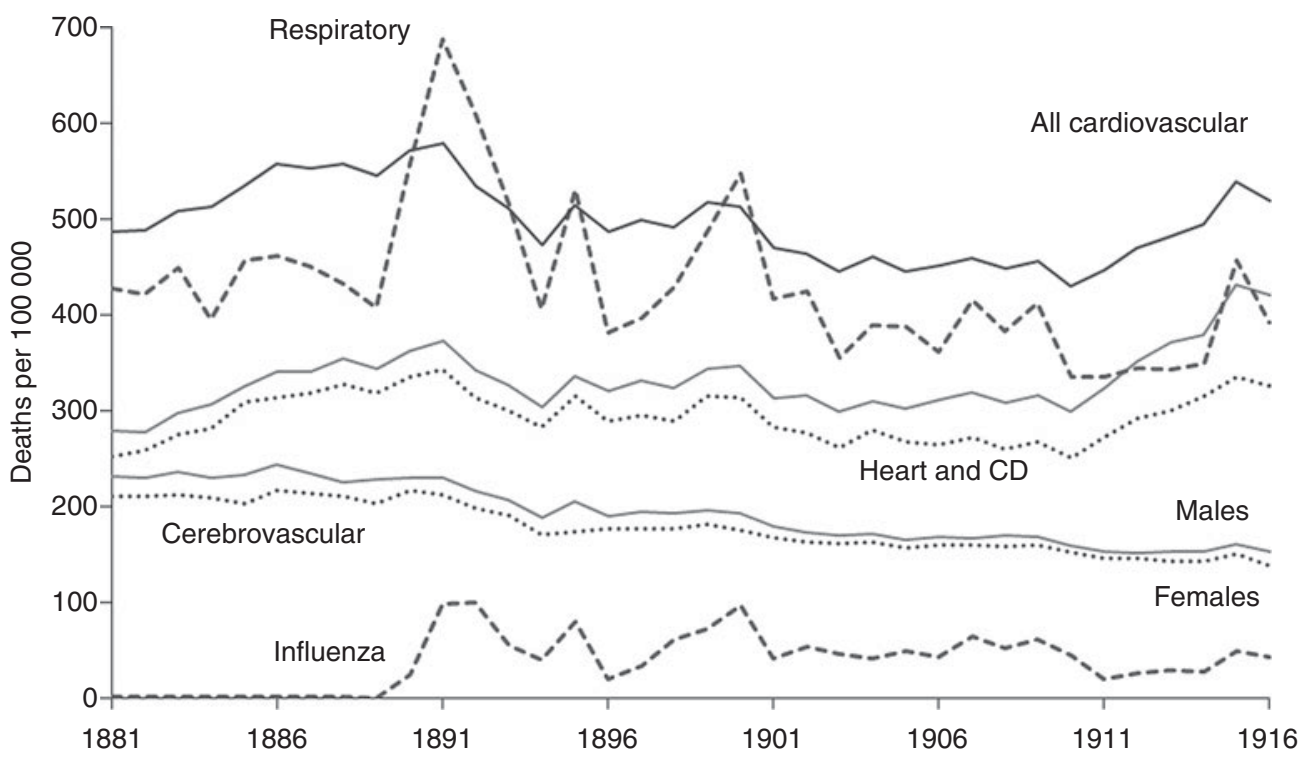

Fig. 1. Annual age-standardized death rates from all cardiovascular disease, heart and circulatory disease (CD), cerebrovascular disease, and respiratory disease (bronchitis, pneumonia, influenza) in England and Wales, 1881-1916.

more prone to distortion due to transfer of certified cause between them. However, there is evidence that errors in diagnosis and classification tend to cancel each other out for large groups such as CVD [53]. Studies have differed with regard to which subcategories to include, although a study of cerebrovascular disease death rates between 1910 and 1996 found that the small number of deaths involved made no visible difference to plotted trends [54]. The ICD codes used for trends presented in that study were used here for 1901-1916 and 1920-1939, while the codes for 1940-2000 were those used by ONS for national trends in stroke mortality [52]. The higher mortality in 1940 was probably due in part to reclassification of some sub-categories of cerebrovascular disease when ICD-5 was introduced [54]. The codes used for the heart disease/CD group were the categories used by ONS for national trends for diseases of the circulatory system [52]. The focus here on the broad group, heart disease and $\mathrm{CD}$, minimizes problems for interpretation of trends due to increasingly specific diagnosis and reclassification, and also allows comparison of later trends with those for 1881-1916 when a specific cause of many heart disease and CD deaths was not recorded, and IHD was not yet a category of disease [54].

The method of age standardization of death rates using the 1976 ESP is also consistent with other studies, and the age distribution was considered reasonably comparable with that of England and Wales until the 1990s [54]. There are limitations in using 


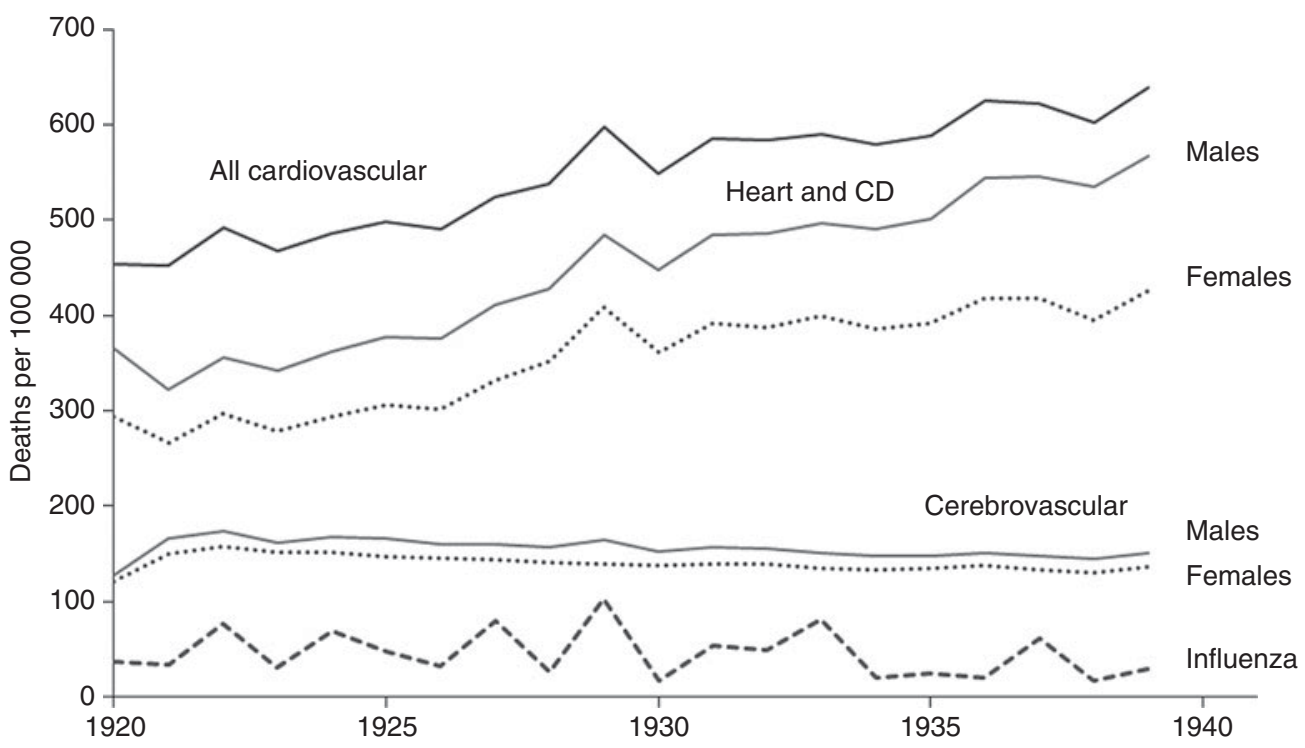

Fig. 2. Annual age-standardized death rates from all cardiovascular disease, heart and circulatory disease (CD), cerebrovascular disease, and influenza in England and Wales, 1920-1939.

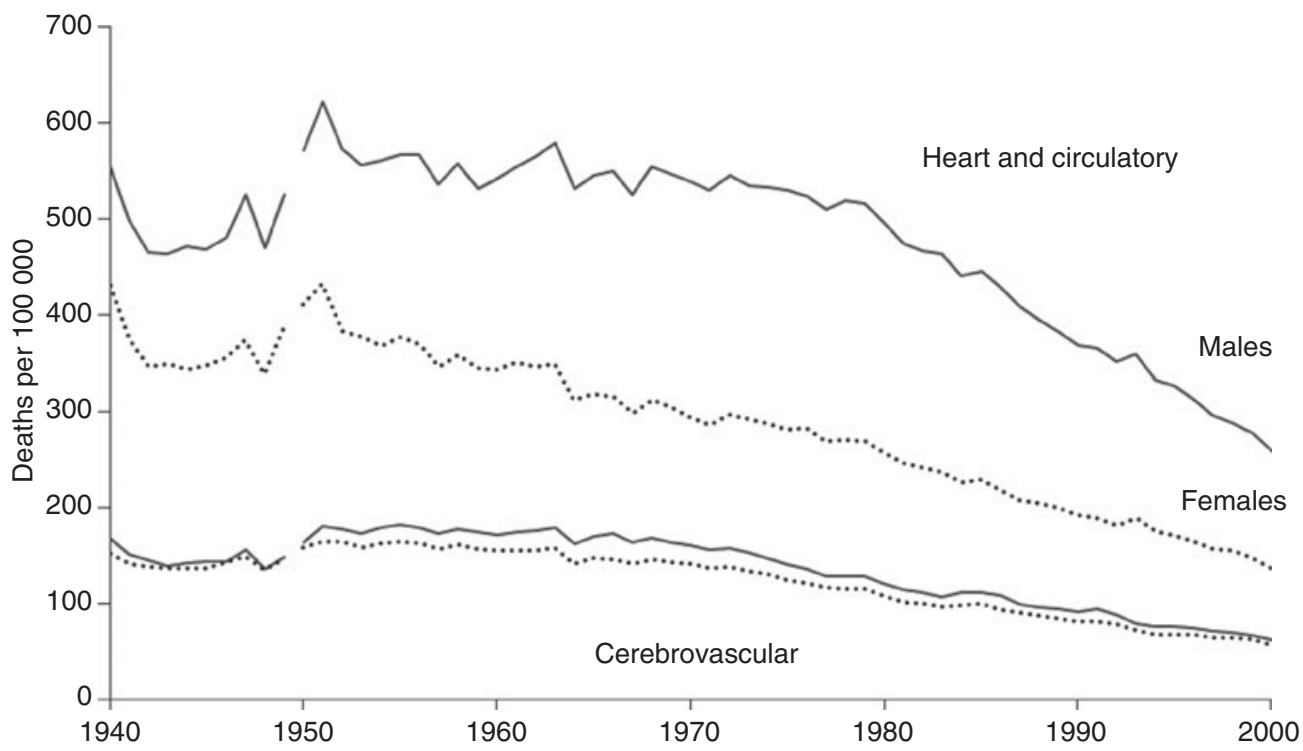

Fig. 3. Annual age-standardized death rates from heart and circulatory disease, and cerebrovascular disease, for males and females in England and Wales, 1940-2000.

the same standard for earlier periods when the age structure was very different, although the advantage is more comparability of the level of standardized death rates over time. The population of England and Wales in 1901 would give age-standardized death rates closer to the actual rates between 1881 and 1916, although when used there was no discernible difference in the broad patterns of change (not shown). The ESP has now been updated (2013) to reflect increasing numbers of people at very old ages, as the high death rates have a relatively strong influence on age-standardized rates [49]. The trend in death rates from CVD reported here largely reflects changes in death rates for ages $\geqslant 45$ years [44]. The secular trends also reflect the aggregate effect of both cohort- and period-related influences. For example, the secular trend in the death rate from respiratory disease (bronchitis, pneumonia, and influenza) reflects experiences earlier in life as well as those closer to the time of death, particularly episodes of infectious 
disease $[44,55]$. However, influences closer to the time of death predominated within the separate timeperiods considered here, which is also the case for heart disease and stroke as indicated by similar patterns of change in death rates for different age groups [54]. Despite changes in diagnostic skills, certification practice, and classification affecting period death rates, the broad patterns of change in agestandardized death rates in the three periods, which are distinctly different, are likely to reflect genuine changes in mortality risk. The extent to which the changes in cardiovascular and respiratory disease mortality reflect changes in incidence cannot be assessed due to lack of data, although short-term fluctuations in influenza mortality are a reasonable indicator of the epidemic cycle.

The importance of viewing recent trends in chronic disease mortality in the historical context of a changing infectious disease environment has been emphasized elsewhere in a review of the epidemiological transition in England [44]. With longer survival due to the prevention of severe infectious diseases, the allcause death rate was declining, and heart disease and stroke accounted for an increasing proportion of all deaths between 1881 and 1950. The increase in the total CVD death rate between 1920 and 1950 reflected increasing heart disease mortality [54], although lower mortality in the 1940s coincided with rationing, which probably reduced risks associated with cigarettes, alcohol, sugar, and other food items. From the 1950s, studies identified the major role of cigarette smoking in the 'heart disease epidemic' [56], and in the widening sex differential in mortality [57, 58], and total cardiovascular mortality started to decline. As both cerebrovascular disease and heart disease/CD death rates declined from 1951 (Fig. 3), transfer of certification between sub-categories does not explain either trend. The decline in the 1960s coincided with preventive interventions focused on reducing the prevalence of cigarette smoking, beneficial changes in diet, and lowering cholesterol levels. Studies in several countries found that the decline in heart disease mortality was associated with reductions in the prevalence of lifestyle-related risk factors and new treatment measures [18-27]. However, statistical models did not account for all the decline, and the benefits of treatment may have been exaggerated by assuming that quantified effects found in randomized trials were replicated in the wider population, and by not taking into account duplication of effects because of multiple life style changes and medical interventions
$[20,23,25]$. Use of aspirin, thrombolysis, drugs for reducing hypertension and harmful cholesterol, and coronary artery bypass surgery have contributed to longer survival for many of those with cardiovascular disorders in recent decades, although a study of IHD mortality in England and Wales concluded that treatment is unlikely to account for a large proportion of the decline in the 1970s and 1980s [54]. A possible contribution of declining prevalence of infections associated with CVD has not been taken into account in epidemiological studies of the recent phase of mortality decline, which for the whole group of heart disease and CD began in 1951 (Fig. 3).

The concomitant decline in death rates from cerebrovascular disease and heart disease/CD between 1891 and 1910 also indicates that transfer of recording between these groups does not explain either trend. The decline in CVD mortality is not explained by transfer of recording to respiratory disease, although some transfer to categories of disease with increasing death rates, such as diabetes mellitus, is possible [44]. The decline occurred despite the likely transfer of recording from the 'old age' and 'ill-defined' categories as certification became more specific, and this probably contributed to the increasing CVD death rate up to 1891 . The decline thereafter is unlikely to be due to deliberate preventive measures or treatment, and that for cerebrovascular disease continued for decades before anti-hypertension treatment was introduced in the 1950s. The early phase predated refrigeration which reduced the need to use salt for food preservation, a suggested cause of hypertension [12]. The downturn in total cardiovascular mortality coincided with that for respiratory disease and measles, contrasting with the earlier onset of decline for many acute infectious diseases and tuberculosis underlying the decline in the overall death rate [44]. Studies in England and developing countries have found that incidence and severity of various types of respiratory infection and measles, which was often complicated with secondary respiratory infections, are higher in crowded households with a large number of children [59-63]. From the 1890s, new housing, reduced overcrowding, and families having fewer children, probably contributed to a decline in severity of these infections, thereby reducing respiratory disease death rates for adults and children, who are often the source of infections introduced into the household [64-67]. High numbers of deaths in older adults recorded as bronchitis or pneumonia contributed to the peak in respiratory disease mortality in the influenza pandemic 
of 1890-1891 [44]. This followed about 40 years of relatively low recording of influenza deaths. The lower respiratory disease death rate after 1891 could reflect the above socio-demographic factors and the level of immunity to strains of influenza virus prevalent in the population. The increase in the death rate between 1910 and 1915 probably reflects other influences on mortality risk as well as the cycle of seasonal influenza.

The correspondence of short-term variation in heart disease/CD mortality with 'spikes' in influenza deaths (Figs 1 and 2), and the similarity between trends in total CVD and respiratory disease death rates between 1881 and 1916, is consistent with other ecological evidence of association. Excess mortality from respiratory disease and heart disease associated with seasonal influenza has been reported for the United States [68, 69], as well as England and Wales [40, 70, 71]. Although some short-term variation may reflect weather conditions [72, 73], many other types of study have found association between heart disease and seasonal influenza or other respiratory infections [35, 36, 38-41]. Many observational studies have provided evidence that generally supports the hypothesis that seasonal influenza can 'trigger' acute myocardial infarction and fatal heart attack [41]. A review of the biological basis for a causal mechanism suggested that in addition to a pro-coagulant effect, infection increases inflammation of the arterial walls, which could destabilize and rupture atherosclerotic plaques leading to embolism and thrombosis [74].

Several studies have suggested that infections have a cumulative role in atherosclerosis [32-35], now widely regarded as an immune-related, inflammatory process contributing to coronary artery disease, stroke, abdominal aortic aneurysm and peripheral vascular disease $[35,37,75]$. Several pathogens have been investigated, including cytomegalovirus and $\mathrm{H}$. pylori, as well as causal agents in respiratory infection. Comprehensive reviews of many types of investigation have found strong evidence of association between atherosclerosis and $H$. pylori [76] or C. pneumoniae [35-37, 77], one of the commonest pathogens causing community-acquired pneumonia worldwide, which probably infects most people at least once [36]. A large prospective population study found a strong association between $C$. pneumoniae and newly developed carotid atherosclerosis, after controlling for common risk factors [78]. Although C. pneumoniae has not been established as a causal agent in atherosclerosis [35, 36], the case for a role in CVD is strengthened by its association with current heart disease [38] and acute myocardial infarction [79], as well as future thickening of carotid arteries [78].

There is little indication of changes in the prevalence of atherosclerosis that might have affected longterm trends in CVD mortality, although changes in thrombotic tendency could have been influential [54]. The association between cerebrovascular disease and H. pylori [42], and between recent respiratory infections and stroke [43, 80], could reflect a prothrombotic effect. The association between heart disease and infection with $C$. pneumoniae appears to be independent of established risk factors and socioeconomic status [38, 79]. Although doubts have been raised about a causal role in the development of heart disease [81, 82], particularly as no association was found between $C$. pneumoniae and future IHD in a prospective study [83], much of the evidence from epidemiological studies, clinical investigations, and patho-physiological observations points to acute infections having a role in cardiovascular disorders. A recent review of evidence found that large, welldesigned studies have consistently reported a two- to three-fold increase in the risk for acute coronary syndromes within 1-2 weeks of respiratory infection. It concluded that acute infections, especially respiratory infections, have a role in triggering strokes and acute coronary events within a causal complex of interacting lifestyle-related factors [84]. A growing body of evidence indicates that infections, and immune responses to them, may have a causal role in the pathogenic processes underlying cardiovascular disorders, heart attacks and stroke. Mixed viral and bacterial infections could contribute to heart disease [28], and multiple pathogens to atherothrombosis [79], while some evidence suggests that the role of infection in CVD might be generic [80].

There is some evidence of reduced risk of potentially fatal cardiovascular events for those with cardiovascular disorders given influenza vaccination $[35,41$, $74,85]$, and evidence of the role of specific pathogens in CVD could come from further research on the effect of child and adult vaccinations on cardiovascular mortality. As young children and those attending school are frequently the source of respiratory infections affecting adults [66, 67], data from programmes of child vaccination against influenza, such as that in Japan which reduced seasonal variation in cardiovascular and respiratory disease mortality [86, 87], could provide further evidence of the impact on CVD in adults [88]. Further vaccination studies in 
low-income countries could provide more definitive evidence of the role in CVD of influenza, pneumonia, C. pneumoniae, and other respiratory pathogens [41, 74, 85, 89, 90]. More than three-quarters of all CVD deaths in the world now occur in countries with average annual per capita income below US $\$ 9000$ (2001) [91]. Established lifestyle-related risk factors such as cigarette smoking, harmful diet, and lack of exercise, are likely to explain much of the increasing burden of cardiovascular morbidity and mortality in low-income countries. The majority of people will not have access to expensive treatment in the foreseeable future, and low-cost prevention strategies are required to promote changes in health-related behaviours that have reduced cardiovascular mortality in industrialized countries.

This study provides evidence of a decline in cerebrovascular and other cardiovascular mortality in England and Wales between 1891 and 1910, long before preventive and treatment measures. This coincided with the beginning of the decline in the death rate from the group of respiratory diseases, bronchitis, pneumonia and influenza. Correspondence between short-term fluctuations in the death rates is further indication of ecological association, which is consistent with evidence from other types of study that seasonal influenza can trigger acute myocardial infarction and episodes of respiratory infection are followed by increased risk of cardiovascular events. Further research is needed to ascertain whether vaccination against infectious diseases, particularly respiratory infections, can contribute to prevention of cardiovascular disorders, heart attack and stroke in individuals, and at the population level.

\section{ACKNOWLEDGEMENTS}

The author is grateful to two anonymous reviewers for their helpful comments and suggestions.

\section{DECLARATION OF INTEREST}

None.

\section{REFERENCES}

1. Uemura K, Pisa Z. Trends in cardiovascular disease mortality in industrialized countries since 1950. World Health Statistics Quarterly 1988; 41: 155-178.

2. De Looper M, Bhatia K. International Health-How Australia Compares. Canberra: Australian Institute of Health and Welfare, 1998.
3. Levi F, et al. Trends in mortality from cardiovascular and cerebrovascular diseases in Europe and other areas of the world. Heart 2002; 88: 119-124.

4. Kesteloot H, Sans S, Kromhout D. Dynamics of cardiovascular and all-cause mortality in Western and Eastern Europe between 1970 and 2000. European Heart Journal 2006; 27: 107-113.

5. McKee M. The health consequences of the collapse of the Soviet Union. In: Leon D, Walt G, eds. Poverty, Inequality and Health: An International Perspective. Oxford: Oxford University Press, 2001, pp. 17-36.

6. Mirzaei M, et al. Coronary heart disease epidemics: not all the same. Heart 2009; 95: 740-746.

7. National Heart Lung and Blood Institute. Report of the Task Force on Research in Epidemiology and Prevention of Cardiovascular Diseases. Rockville, Maryland: National Institutes of Health, 1994.

8. Marmot MG, et al. Contribution of job control and other risk factors to social variations in coronary heart disease incidence. Lancet 1997; 350: 235-239.

9. Marmot MG, et al. Changing social-class distribution of heart diseases. British Medical Journal 1978; 2: 1109-1112.

10. Mackenbach JP, et al. Geographic variation in the onset of decline of male ischaemic heart disease mortality in the Netherlands. American Journal of Public Health 1989; 79: 1621-1627.

11. Gale CR, Martyn CN. The conundrum of time trends in stroke. Journal of the Royal Society of Medicine 1997; 90: $138-143$.

12. Whisnant JP. The decline of stroke. Stroke 1984; 15: $160-168$

13. La Vecchia C, Levi F. Trends in cerebrovascular mortality in western and eastern Europe. European Neurology 1994; 34: 301-305.

14. Centers for Disease Control. Achievements in public health, 1900-1999: decline in deaths from heart disease and stroke - United States, 1900-1999. Morbidity and Mortality Weekly Report 1999; 48: 649-656.

15. Bonita R, Beaglehole R. Increased treatment of hypertension does not explain the decline in stroke mortality in the United States, 1970-1980. Hypertension 1989; 3 (5 Suppl.): I-69-I-73.

16. Haberman S, Capideo R, Rose FC. Diverging trends in cerebrovascular disease and ischaemic heart disease mortality. Stroke 1982; 13: 582-589.

17. Walker WJ. Changing United States life-style and declining vascular mortality: cause or coincidence? New England Journal of Medicine 1977; 297: 163-165.

18. Stamler J. The marked decline in coronary heart disease mortality rates in the United States, 1968-1981; summary of findings and possible explanations. Cardiology 1985; 72: 11-22.

19. Kannel WB, Thom TJ. Declining cardiovascular mortality. Circulation 1984; 70: 331-336.

20. Goldman L, Cook E. The decline in ischaemic heart disease mortality rates: an analysis of the comparative effects of medical interventions and changes in lifestyle. Annals of Internal Medicine 1984; 101: 825-836.

21. Huninck MG, et al. The recent decline in mortality from coronary heart disease, 1980-1990: the effect of secular 
trends in risk factors and treatment. Journal of the American Medical Association 1997; 277: 535-542.

22. Ford ES, et al. Explaining the decrease in US deaths from coronary disease, 1980-2000. New England Journal of Medicine 2007; 356: 2388-2398.

23. Unal B, Critchley JA, Capewell S. Explaining the decline in coronary heart disease mortality in England and Wales between 1981 and 2000. Circulation 2004; 109: 1101-1107.

24. Bots ML, Grobbe DE. Decline of coronary heart disease mortality in the Netherlands from 1978 to 1985: contribution of medical care and changes over time in presence of major cardiovascular risk factors. Journal of Cardiovascular Risk 1996; 3: 271-276.

25. Bjorck L, et al. Modelling the decreasing coronary heart disease mortality in Sweden between 1986 and 2002. European Heart Journal 2009; 30: 1046-1056.

26. Capewell S, Morrison CE, McMurray JJ. Contribution of modern cardiovascular treatment and risk factor changes to the decline in coronary heart disease mortality in Scotland between 1975 and 1994. Heart 1999; 81: 380-386.

27. Capewell S, et al. Explaining the decline in mortality from coronary heart disease in Auckland, New Zealand between 1982 and 1993. Circulation 2000; 102: 15111516.

28. Burch GE, Giles TD. The role of viruses in the production of heart disease. American Journal of Cardiology 1972; 29: 231-239.

29. Lu Wan Ching. Agglutination of human platelets by influenza PR8 strain virus and mumps virus. Federation Proceedings 1958; 17: 446.

30. Mustard JF. Platelets and thromboembolic disease. Advances in Cardiology 1970; 4: 131-142.

31. Genton E, Wiley HS, Steele PP. Platelets, thrombosis and coronary artery disease. Advances in Cardiology 1973; 9: 29-39.

32. Mustard JF, et al. Platelets and atherosclerosis. Journal of Atherosclerosis Research 1964; 4: 1-28.

33. Benditt EP, Benditt JM. Evidence for a monoclonal origin of human atherosclerotic plaques. Proceedings of the National Academy of Sciences USA 1973; 70: 17531756.

34. Nieto FJ. Infections and atherosclerosis: New clues from an old hypothesis? American Journal of Epidemiology 1998; 148: 937-947.

35. Morré SA, et al. Microorganisms in the aetiology of atherosclerosis. Journal of Clinical Pathology 2000; 53: 647-654.

36. Campbell LA, Kuo C, Grayston JT. Chlamydia pneumoniae and cardiovascular disease. Emerging Infectious Diseases 1998; 4: 571-579.

37. Ngeh J, Anand V, Gupta S. Chlamydia pneumoniae and atherosclerosis - what we know and what we don't know. Clinical Microbiology and Infection 2002; 8: 2-13.

38. Patel P, et al. Association of Helicobacter pylori and Chlamydia pneumoniae infections with coronary heart disease and cardiovascular risk factors. British Medical Journal 1995; 311: 711-714.
39. Bainton D, Jones GR, Hole D. Influenza and ischaemic heart disease - a possible trigger for acute myocardial infarction? International Journal of Epidemiology 1978; 7: $231-239$.

40. Fleming DM, Cross KW, Pannell RS. Influenza and its relationship to circulatory disorders. Epidemiology and Infection 2005; 133: 255-262.

41. Warren-Gash C, Smeeth L, Hayward AC. Influenza as a trigger for acute myocardial infarction or death from cardiovascular disease: a systematic review. Lancet Infectious Diseases 2009; 9: 601-610.

42. Markus HS, Mendall MA. Helicobacter pylori infection: a risk factor for ischaemic cerebrovascular disease and carotid atheroma. Journal of Neurology, Neurosurgery and Psychiatry 1998; 64: 104-107.

43. Grau AJ, et al. Recent infection as a risk factor for cerebrovascular ischaemia. Stroke 1995; 26: 373-379.

44. Mercer A, Infections, Chronic Disease, and the Epidemiological Transition. A New Perspective. Rochester Studies in Medical History. Rochester NY: University of Rochester Press, 2014.

45. Clayton DG, Taylor D, Shaper AG. Trends in heart disease in England and Wales, 1950-73. Health Trends 1977; 9: 1-6.

46. Nikiforov SV, Mamaev VB. The development of sex differences in cardiovascular disease mortality: a historical perspective. American Journal of Public Health 1998; 88: $1348-1353$.

47. Registrar General for England and Wales. Annual Report for England and Wales, 1875-1899; Annual Statistical Review for England and Wales, 1900-. London: HMSO.

48. Office for National Statistics, UK Statistics Authority. Twentieth Century Mortality. CD-ROM. Newport, Wales: Office for National Statistics; Norwich: Stationery Office Books, 2004.

49. European Commission, Eurostat. Revision of the European Standard Population. Luxembourg: Publications Office of the European Union, 2013.

50. Janssen F, Kunst AE. ICD coding changes and discontinuities in trends in cause-specific mortality in six European countries, 1950-99. Bulletin of the World Health Organisation 2004; 82: 904-913.

51 Centers for Disease Control and Prevention. Comparability of Cause-of-death Between ICD Revisions. Table for selected causes. National Center for Health Statistics, United States (www.cdc.gov/nchs/data/dvs/comp2.pdf).

52. Griffiths C, Brock A. 20th century mortality trends in England and Wales. Health Statistics Quarterly 2003; 18: $5-17$.

53. Waldron HA, Vickerstaff L. Intimations of Quality: Ante Mortem and Post Mortem Diagnoses. London: Nuffield Provincial Hospitals Trust, 1977.

54. Charlton J, et al. Cardiovascular diseases. In: Charlton J, Murphy M, eds. The Health of Adult Britain 1841-1994, Volume 2. London: The Stationery Office, 1997, pp. 60-81.

55. Marks G, Burney P. Diseases of the respiratory system. In: Charlton J, Murphy M, eds. The Health of Adult Britain 1841-1994, Volume 2. London: The Stationery Office, 1997, pp 93-113. 
56. Doll R, et al. Mortality in relation to smoking: 50 years' observations on male British doctors. British Medical Journal 2004; 328: 1519-1533.

57. Preston SH. International comparisons of excessive adult mortality. Population Studies 1970; 24: 5-20.

58. Retherford RD. The Changing Sex Differential in Mortality. Studies in Population and Urban Demography No. 1. Connecticut: Greenwood, 1975.

59. Aaby P, et al. Severe measles in Sunderland, 1885: A European-African comparison of causes of severe infection. International Journal of Epidemiology 1986; 15: 101-107.

60. Aaby $\mathbf{P}$, et al. Overcrowding and intensive exposure as determinants of measles mortality. American Journal of Epidemiology 1984; 120: 49-63.

61. Gardner G, Frank AL, Taber LH. Effects of social and family factors on viral respiratory infection and illness in the first year of life. Journal of Epidemiology and Community Health 1984; 38: 42-48.

62. Berman S. Epidemiology of acute respiratory infections in children in developing countries. Reviews of Infectious Diseases 1991; 13 (Suppl. 6): S454-462.

63. Simoes EA. Environmental and demographic risk factors for respiratory syncytial virus lower respiratory tract disease. Journal of Pediatrics 2003; 143 (5 Suppl.): S118-126.

64. Burnett J. Housing and the decline in mortality. In Schofield RD, Reher D, Bideau A, eds. The Decline of Mortality in Europe. Oxford: Clarendon Press, 1991.

65. Mercer AJ. Relative trends in mortality from related respiratory and airborne infectious diseases. Population Studies 1986; 40: 129-145.

66. Brimblecombe FSW, et al. Family studies of respiratory infections. British Medical Journal 1958; 1: 119-128.

67. Longini IM, et al. Estimating household and community transmission parameters for influenza. American Journal of Epidemiology 1982; 115: 736-751.

68. Alling DW, Blackwelder WC, Stuart-Harris CH. A study of excess mortality during influenza epidemics in the United States, 1968-1976. American Journal of Epidemiology 1981; 113: 30-42.

69. Reichert TA, et al. Influenza and the winter increase in mortality in the United States, 1959-1999. American Journal of Epidemiology 2004; 160: 492-502.

70. Tillett HE, Smith JWG, Gooch CD. Excess deaths attributable to influenza in England and Wales: age at death and certified cause. International Journal of Epidemiology 1983; 12: 344-352.

71. Stocks P. The effect of influenza epidemics on the certified causes of death. Lancet 1934; 2: 1331-1340.

72. Bull GM. Meteorological correlates with myocardial and cerebral infarction and respiratory diseases. British Journal of Preventive and Social Medicine 1973; 27: 108-113.

73. West RR, Lloyd S, Roberts CJ. Mortality from ischaemic heart diseases: association with the weather. British Journal of Preventive and Social Medicine 1973; 27: $36-40$.
74. Madjid M, et al. Influenza and cardiovascular disease is there a causal relationship? Texas Heart Institute Journal 2004; 31: 4-13.

75. Ross R. Atherosclerosis - an inflammatory disease. New England Journal of Medicine 1999; 340: 115-125.

76. Karbasi-Afshar R, Khedmat H, Izadi M. Helicobacter pylori infection and atherosclerosis: a systematic review. Acta Medica Iranica 2015; 53: 78-88.

77. Kalayoglu MV, Libby P, Byrne GI. Chlamydia pneumoniae as an emerging risk factor in cardiovascular disease. Journal of the American Medical Association 2002; 288: 2724-2731.

78. Kiechl S, et al. Chronic infections and the risk of carotid atherosclerosis. Circulation 2001; 103: 1064-1070.

79. Heltai K, et al. Elevated antibody levels against Chlamydia pneumoniae, human HSP60 and mycobacterial HSP65 are independent risk factors in myocardial infarction and ischaemic heart disease. Atherosclerosis 2004; 173: 339-346.

80. Smeeth L, et al. Risk of myocardial infarction and stroke after acute infection or vaccination. New England Journal of Medicine 2004; 351: 2611-2618.

81. Danesh J, et al. Low grade inflammation and coronary heart disease: prospective study and updated metaanalyses. British Medical Journal 2000; 321: 199-204.

82. Danesh J, Collins R, Peto R. Chronic infections and coronary heart disease: is there a link? Lancet 1997; 350: 430-436.

83. Wald NJ, et al. Chlamydia pneumoniae infection and mortality from ischaemic heart disease: large prospective study. British Medical Journal 2000; 321: 204-207.

84. Corrales-Medina VF, Madjid M, Musher DM. Role of acute infection in triggering acute coronary syndromes. Lancet Infectious Diseases 2010; 10: 83-92.

85. Madjid M. Acute infections, vaccination and prevention of cardiovascular disease. Canadian Medical Association Journal 2008; 179: 749-750.

86. Reichert TA, et al. The Japanese experience with vaccinating schoolchildren against influenza. New England Journal of Medicine 2001; 344: 889-896.

87. Reichert TA, Sharma A. The seasonability of human mortality: the role of influenza. International Congress Series 2001; 1219: 95-101.

88. Madjid M, et al. Influenza and cardiovascular disease. A new opportunity for prevention and the need for further studies. Circulation 2003; 108: 2730-2736.

89. Keller T, et al. Influenza vaccines for preventing coronary heart disease. Cochrane Database of Systematic Reviews 2008. Issue 3, Art. No.: CD005050. doi: 10.1002/14651858.CD005050.pub2.

90. Lamontagne F, et al. Pneumonococcal vaccination and risk of myocardial infarction. Canadian Medical Association Journal 2008; 179: 773-777.

91. Beaglehole R. Poverty and human development: the global implications of cardiovascular disease. Circulation 2007; 116: 1871-1873. 